\title{
UM ENSAIO SOBRE A PROFISSIONALIZAÇÃO DOCENTE
}

\author{
Karina Melissa Cabral ${ }^{1}$
}

\begin{abstract}
RESUMO
A profissionalização da atividade docente é o foco de análise e discussão deste texto, a finalidade é tentar assinalar as tendências e as contradições relativas às dimensões pedagógicas e políticoeducacionais da profissão, levando em consideração os novos desafios da profissão.
\end{abstract}

\section{INTRODUÇÃO}

Há, ainda hoje, inegavelmente a concepção de que a docência equipara-se ao sacerdócio, a uma missão, conforme pautava o entendimento popular majoritário do início do século XX. Pacheco (2004) também evidencia esta constatação:

Leio num jornal uma frase absurda: ' $O$ que me irrita são as greves dos professores do ensino fundamental e médio, por estas serem profissões onde se está por paixão'. Não comento o conteúdo acusatório de toda uma profissionalidade docente, tão só que o ensino e a educação ainda são vistos pela janela do sacerdócio, como se a escola fosse um local de perdoar pecados e tratar dos problemas da alma.

Além desta visão sacerdotal, existe ainda, uma outra dicotomia no que se refere à profissionalização docente, que é o embate entre a lógica da qualificação, imposta pelo discurso mercadológico, no qual há a ênfase na racionalidade técnica, baseada na produtividade e na competição e as concepções fundamentadas no professor como produto e produtor, segundo a epistemologia da prática, no entendimento de que ao professor, segundo Perrenoud (1999, p. 184, apud ALMEIDA, 1999, p. 12), “não cabe ensinar somente a ler, a escrever e a contar, mas também a tolerar e a respeitar as diferenças, a coexistir, a raciocinar, a comunicar, a cooperar, a mudar, a agir de forma eficaz”.

Assim, é diante do último paradigma que este estudo se desenvolverá, inicialmente analisando o que Pacheco (2004) denomina por pedagogia das competências, em seguida

1 Karina Melissa Cabral é Advogada; autora do Livro Direitos da Mulher: de acordo com o Novo Código Civil; Membro da Comissão da Mulher Advogada da Subsecção de Osvaldo Cruz, OAB/SP; Pós-graduanda em Docência do Ensino Superior pela Toledo de Araçatuba/SP; Mestranda em Educação pela Unesp de Presidente Pudente/SP. 
vislumbrando a profissionalidade docente, apontando alguns dos novos saberes necessários a esta concepção de docência contemporânea.

\section{A PEDAGOGIA DAS COMPETÊNCIAS}

Atualmente, há uma tendência advinda do neo-capitalismo de atribuir aos docentes e à escola essencialmente a função de formar indivíduos aptos ao mercado de trabalho, tendência esta denominada por Singer (1996, apud LEITE e DI GIORGI, 2004) como produtivista. E, conforme expõem Leite e Di Giorgi (2004) “a tendência produtivista [...] tem propensão a diminuir o papel do professor e propor para ele uma formação mais tecnicista e estreita”.

As próprias políticas educacionais têm seus conteúdos ligados à eficiência e à qualidade centrada em resultados, neste sentido, Freitas (2004, p. 1097) acrescenta que:

No campo da formação dos profissionais da educação, estamos vivenciando o que poderíamos configurar como o retorno às concepções tecnicistas e pragmatistas da década de 1970, agora em um patamar mais avançado, deslocando o referencial da qualificação do emprego - qualificação profissional - para a qualificação do indivíduo - em que a concepção neoliberal de competência tem levado a centrar os processos de formação no desenvolvimento de competências comportamentais

Assim, este discurso mercadológico educacional é denominado por Pacheco (2004) como pedagogia das competências, nos seguintes termos "por estar inscrita na agenda curricular tanto da formação docente quanto do controle da aprendizagem escolar, decorre de um modelo de gestão científica, tornando-se, por isso, num instrumento que reforça não só a racionalidade técnica, mas também as práticas pedagógicas que delimitam o processo ensino/aprendizagem como um dispositivo que é justificado pela transmissão e pelo prolongamento da pedagogia por objetivos”.

A atual sociedade do conhecimento nos coloca como desafio não só a uniformidade da formação docente e a estandardização de competências, assim como sugere Hargreaves (2004, p. 94 apud PACHECO, 2004), mas também a problematização do docente como pessoa, através de sua luta contínua pela construção de uma profissionalidade autônoma. É notório que esta luta de professores e formadores permeia e envolve a qualidade dos processos de ensino-aprendizagem dos alunos. 


\section{A PROFISSIONALIDADE DOCENTE}

A discussão sobre a profissionalidade docente têm sido recorrente nos discursos dos educadores contemporâneos, tanto nas produções nacionais quanto internacionais e, neste sentido, como propõe Cunha (1999, p. 217) tem-se apresentado diferentes adjetivos aos professores com o intuito de explicitar a concepção que se projeta para o seu trabalho, tentando fugir da lógica liberal-mercadológica que tem envolvido a profissionalização docente. Exemplos disso são o professor prático-reflexivo de Schön, Zeichener, Nóvoa, Elliot; o intelectual radical de Giroux; o artista/artesão de Eisner e Pérez Gomes; o investigador de Stenhouse; o investigador em ação de Carr e Kemmis; o indagador clínico de Smyth e Clark e o professor emancipador de Freire.

Na realidade, todas estas concepções alicerçam-se numa epistemologia da prática, onde cabe ao professor refletir sobre sua própria prática docente, a propósito de sua realidade social e educativa, tratando-se, portanto, de um exercício processual. O professor deixa de ser um reprodutor mecânico do conhecimento e passa a buscar em sua vivência docente a solução para os seus problemas.

Cunha (1999, p. 217) ainda salienta uma outra característica comum entre estas teorias que é a valorização dos sujeitos da educação.

Neste sentido devemos nos apropriar do termo profissionalidade docente nas bases propostas por Sacristán (1998, p. 54 apud CUNHA, 1999, p. 216) que nos traz que a profissionalidade é a "expressão da especificidade da atuação dos professores na prática, isto é, o conjunto de atuações, destrezas, conhecimentos, atitudes e valores ligados a ela que constituem o específico de ser professor”, considerando que a docência não é estática ou imutável, muito pelo contrário, é dinâmica envolvendo sempre um processo com novos atores, novas experiências, novos contextos e novos tempos.

É importante salientar que na formação de um professor, na construção desta profissionalidade, se registra, segundo Doly (1999, p. 21, apud PACHECO, 2004), um processo metacognitivo, isto é, um processo de articulação da teoria com a prática em que a atividade de conhecimento se torna objeto de reflexão.

Desta forma, assim como coleciona Cunha (1999, p. 218), diante do atual paradigma da sociedade complexa, o professor assume uma nova profissionalidade de caráter interpretativo, sendo uma ponte entre o conhecimento sistematizado, os saberes da prática social e a cultura onde acontece o ato educativo, incluindo as estruturas sócio-cognitivas do aluno. 
Segundo Contreras (2002, p. 192 apud LEITE e DI GIORGI, 2004), é necessário resgatar a base reflexiva da atuação profissional com o objetivo de entender a forma em que realmente se abordam as situações problemáticas da prática. Assim, o professor terá mais condições de compreender o contexto social no qual ocorre o processo de ensino/aprendizagem, contexto este onde se mesclam diferentes interesses e valores, bem como maior clareza para examinar criticamente a natureza e o processo da educação instalado no país.

Giroux (1998, p. 163 apud LEITE e DI GIORGI, 2004) afirma que o essencial para o professor é a necessidade de tornar o pedagógico mais político e o político mais pedagógico. Tornar o pedagógico mais político significa considerar a educação escolarizada sob o enfoque político, possibilitando que a escola torne-se parte do projeto social mais amplo, com o objetivo de ajudar os alunos a se desenvolverem para que as injustiças econômicas, políticas e sociais sejam superadas. Tornar o político mais pedagógico significa utilizar formas de ensinar que incorporem os interesses políticos de natureza emancipadora. Implica tratar o aluno como agente crítico, capaz de problematizar o conhecimento e de utilizar o diálogo crítico, argumentando em prol de um mundo qualitativamente melhor para todas as pessoas.

Como se evidencia, há toda uma preocupação na literatura educacional para redimensionar a profissão docente num sentido mais ético e autônomo, considerando como saberes necessários para esta constituição a consciência, a compreensão e o conhecimento, saberes esses nos quais a reflexidade deve se basear para uma perspectiva emancipatória da profissão.

Assim, concordo com a colocação de Cunha (1999, p. 223) quando esta propõe que a constatação das forças que contradizem as utopias que alimentamos não podem ser barreiras para o empenho de mudanças, pois apenas nos ajudam a perder a ingenuidade; a compreensão da macro-estrutura de poder, definidora das políticas públicas para o país deve, acima de tudo, nos instrumentalizar para a resistência e para preencher os espaços de contradição. Isto porque, esta está a exigir muito mais do que a competência instrumental, esta requer compromisso e vontade.

Concluindo, conforme Leite e Di Giorgi (2004) esta mudança na profissionalidade docente, não é suficiente, ela é certamente necessária. 
ALMEIDA, M. I. de. O sindicato como instância formadora dos professores: novas contribuições ao desenvolvimento profissional. 1999. Tese (Doutorado em Educação) Faculdade de Educação, Universidade de São Paulo. 220p.

CARR, W; KEMMIS, S. Teoria Crítica de la Enseñanza. Barcelona, Ediciones Martinez Roca,1988.

CONTRERAS, J. A Autonomia de Professores. São Paulo: Cortez, 2002.

CUNHA, M. I. da. Trabalho Docente e Ensino Superior. In: RAYS, Oswaldo Alonso (Org.). Trabalho Pedagógico: realidades e perspectivas. Porto Alegre: Editora Sulina, 1999.

et al. Autonomia e Autoridade em Diálogo com a Teoria e a Prática: o caso da profissão docente. Revista do Centro de Educação, ed. 2004, vol. 29, nº 02, Disponível em: http://www.ufsm.br/ce/revista/revce/2004/02/a5.htm. Acesso em 24.05.2006.

EISNER, E. The Educational Imagination. New York: Macmillan, 1979.

ELLIOTT, J. La investigación-acción en Educación. Madrid: Ed. Morata, 1990.

FREIRE, P. Ação Cultural Para a Liberdade. Rio de Janeiro: Paz e Terra,1982.

Pedagogia da Autonomia: saberes necessários à prática educativa. São Paulo: Paz e Terra, 1996.

Pedagogia do Oprimido. Rio de Janeiro: Paz e Terra, 1979.

FREITAS, H. de. Certificação do docente e formação do educador: regulação e desprofissionalização. Educação \& Sociedade (2004), 24 (85), p. 1095-1124.

GIROUX, H. A. Os professores como intelectuais - rumo a uma pedagogia crítica da aprendizagem. Porto Alegre: Artmed, 1997.

LEITE, Y. U. F.; DI GIORGI, C. A. G. Saberes Docentes de um Novo Tipo na Formação Profissional do Professor: alguns apontamentos. Revista do Centro de Educação, ed. 2004, 
vol. 29, no 02, Disponível em: http://www.ufsm.br/ce/revista/revce/2004/02/a10.htm. Acesso em 24.05.2006.

NÓVOA, A. Os professores e sua formação. Lisboa: Dom Quixote, 1992.

Relação Escola-Sociedade: novas respostas para um velho problema. In: SERBINO, R. V. et al. Formação de professores. São Paulo, Fundação Editora da UNESP, 1998 (seminários e debates).

O passado e o presente dos professores. In: NÓVOA, A. (Org.). Profissão Professor. 2 ed. Portugal/ Porto, Porto Editora, 1995.

Para o estudo sócio-histórico da gênese e desenvolvimento da profissão docente. In:

Revista Teoria \& Educação - Dossiê Interpretando o trabalho docente, Porto Alegre, Editora Pannonica, n. 4, 1991.

A formação profissional dos professores. IN: NÓVOA, A. (Org.) Profissão Professor. 2 ed. Porto/Portugal: Porto Editora, 1995.

PACHECO, J. A. A (difícil) Construção da Profissionalidade Docente. Revista do Centro de Educação, ed. 2004, vol. 29, $\mathrm{n}^{0} \quad$ 02, Disponível em: http://www.ufsm.br/ce/revista/revce/2004/02/a1.htm. Acesso em 24.05.2006.

PEREZ GÓMEZ. A. I. A cultura escolar na sociedade neoliberal. Porto Alegre: ARTMED, 2001.

A. I. Calidad de la enseñanza y desarrollo profesional del docente. In: NÓVOA, A. (Coord.) Os professores e sua formação. Lisboa: Dom Quixote, 1997.

SCHÖN, D. Educando o profissional reflexivo: um novo design para o ensino e a aprendizagem. Porto Alegre, ARTMED, 2000.

STENHOUSE, L. Investigación y desarrollo del currículo. Madrid : Morata, 1984.

La investigación como base de la enseñanza. Madrid : Morata, 1987. 
ZEICHNER, K. Formando professores reflexivos para uma educação centrada no aprendiz: possibilidades e contradições. In: ESTEBAN, M. T; ZACCUR, Edwiges (Org.). Professora pesquisadora: uma práxis em construção. Rio de Janeiro: DP\&A, 2002. 